\title{
Object-based approach for urban land cover mapping using high spatial resolution data
}

\author{
Malgorzata Verone Wojtaszek ${ }^{1, *}$, Levente Ronczyk ${ }^{2}$, Zokhid Mamatkulov ${ }^{3}$, and \\ Mamanbek Reimov ${ }^{3}$ \\ ${ }^{1}$ OU Alba Regia Technical Faculty, Pirosalma str. 1-3, 8000 Székesfehérvár, Hungary \\ ${ }^{2}$ UP Faculty of Sciences Institute of Geography, Ifjúság str. 6. 7624 Pécs, Hungary \\ ${ }^{3}$ Tashkent Institute of Irrigation and Agricultural Mechanization Engineers (TIIAME), Koriy Niyaziy \\ str., 39, 100000, Tashkent, Uzbekistan.
}

\begin{abstract}
This paper deals with object-oriented image analysis applied for an urban area. Very high-resolution images in conjunction with objectoriented image analysis have been used for land cover detection. Using the eCognition software with object-oriented methods, not only the spectral information but also the shape, compactness and other parameters can be used to extract meaningful objects. The spectral and geometric diversity of urban surfaces is a very complex research issue. It is the main reason why additional information is needed to improve the outcome of classification. The most consistent and relevant characteristic of buildings is their height. Therefore, elevation data (converted from LIDAR data) are used for building extraction, segmentation and classification. The study deals with the problem, how to determine the most appropriate parameters of segmentation, feature extraction and classification methods. The data extraction includes two phases, the first part consists the following steps: data pre-processing, rule set development, multi-scale image segmentation, the definition of features used to map land use, classification based on rule set and accuracy evaluation. The second part of the data process based on classical raster analysis GIS tools like focal and zonal function.
\end{abstract}

Keywords: OBIA, GIS, remote sensing, land cover, urban environment, zonal statistics

\section{Introduction}

The loss of natural and semi-natural ecosystems and hereby induced negative change in the environment are among the most actual problems nowadays. In the last decades the rapid increase of large cities and the transformation of urban landscapes are the grates challenges to human welfare and a viable global environment. Urbanization is the most visible anthropogenic force on the earth, affecting its surface, atmosphere, water, its biodiversity and the life of people. There needed reliable data to assess the ecosystem health and biodiversity of many urban areas. The town planning and city management requires wide spectrum of topographical, environmental, infrastructure and several other

* Corresponding author: wojtaszek.malgorzata@amk.uni-obuda.hu 
information as well. Remote sensing provides an important data source for many fields of research. Data available from satellites presents an opportunity to collect information relevant to urban environments at various of spatial and temporal scales. Urban land cover and land use data play an important role in ecological and environmental investigations. In several studies remote sensing data are used as a source, but the results are not quite satisfying for detailed land use detection in urban areas [6, 8, 14-17,]. Many studies have been carried out to find an appropriate method to classify the high resolution remote sensing data $[3,7,12-13]$. The difficulty of mapping land cover in urban environment is not due to the classification methods (algorithms). The problem is related to the creation and selection of features. It is very difficult to find out the representative features or training samples for man-made objects. Recent sensor development including high spatial and spectral resolution like WorldView sensors have the potential for more detailed and accurate mapping of urban land cover and land use [4]. Number of study have focused on the issues of spectral properties of urban materials and their representation and mapping from remote sensing data. The results indicate highly complex and diverse spectral properties of urban land cover types. The spectral reparability of urban land cover types is strongly dependent on spectral sensor characteristics [18]. The development of classification methodologies for analysis of high resolution satellite imagery is relevant to studies related with mapping of urban environments [11-12].

High-resolution satellite images provide an important data source for many fields of research. The difficulty of mapping land cover in urban environment is not due to the classification methods (algorithms). The problem is related to the creation and selection of features. It is very difficult to find out the representative training samples or features for man-made objects. The present study aims at finding an appropriate classification method in order to map urban land cover based on high resolution remote sensing data. This paper deals with object-oriented image analysis applied for an urban area. Very high-resolution aerial photos and satellite images in conjunction with object-oriented image analysis have been used for land cover detection. Using the eCognition software with object-oriented methods, not only the spectral information but also the shape, compactness and other parameters can be used to extract meaningful objects. The spectral and geometric diversity of urban surfaces is a very complex research issue. It is the main reason why additional information is needed to improve the outcome of classification. The most consistent and relevant characteristic of buildings is their high. The elevation data are suitable for building and the different vegetation levels extraction, segmentation and classification.

\section{Materials and methods}

The study area (Székesfehérvár) is situated in central Hungary and one of the largest settlements in Transdanubia (Fig.1). It is the county seat, the cultural and economic centre of Fejér County. According to the historical documents the place has been inhabited since the 5th century BC, but Székesfehérvár was first mentioned in 1009, as Alba Civitas. After World War II the city was subject to industrialization. Parallel with industrialization the population was also growing. By the 1970s Székesfehérvár had swelled to more than 100,000 inhabitants (in 1945 it had only about 35,000.) The city and its surroundings were the most dynamically growing regions of Hungary in the 1990's. A number of new housing estates were built, but the city centre was able to preserve its Baroque character. It is inhabited by 101,943 people [5], the density of population is 594-person/sq $\mathrm{km}$ and ranks among the middle-sized cities of the country. With a total area of $170.9 \mathrm{sq} \mathrm{km}$ it is the second largest county centre in the Transdanubian region. 


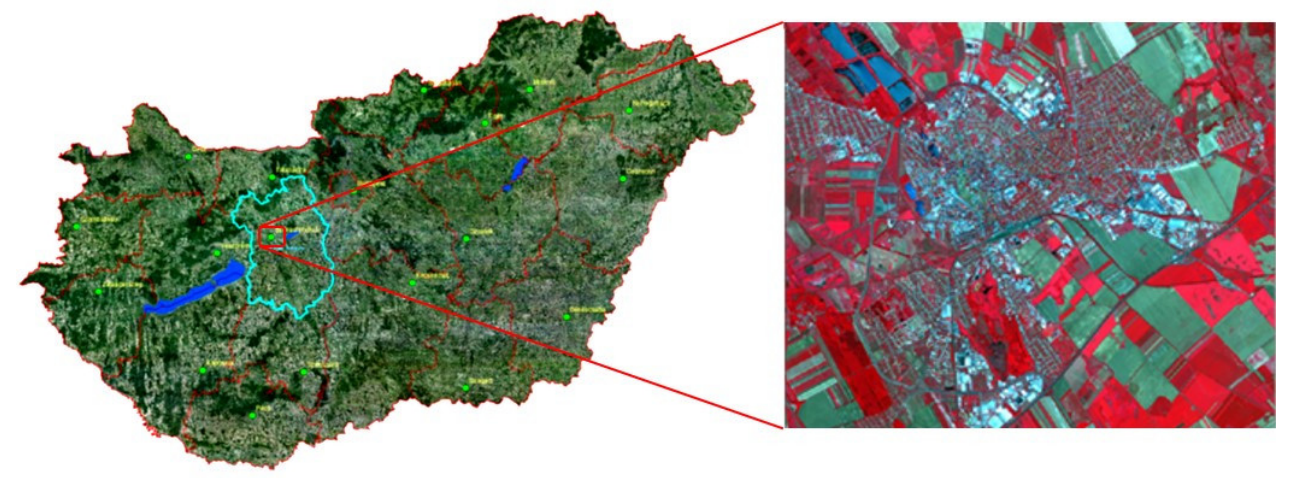

Fig. 1. Study area: Székesfehérvár (Hungary)

\subsection{Data source}

The study used the following remote sensing data:

- WorldView2 satellite image $(2011,2017)$

- Airborne photographs $(2008,2009,2015)$

- LIDAR data (2008)

WorldView-2 developed by DigitalGlobe, USA, in 2009, is the first high resolution multispectral commercial satellite having eight spectral sensors from the visible to nearinfrared range. Spatial resolution of the Pan is $0.5 \mathrm{~m}$ and MS sensors is $2.0 \mathrm{~m}$. WorldView2 image was acquired 2011 and 2017.

In 2008 the inner part of the city Székesfehérvár was laser scanned and in parallel with the laser scanning a digital airborne photographs were taken in visible and in NIR spectra. The images cover an area of $5 \mathrm{~km} 2$. The air photo made in 2009 covered all study area. Both of the airborne datasets were acquired in similar spatial resolution of approximately $0.5 \mathrm{~m}$. The Lidar points measured directly from the field, their point original density is 6-8 point $/ \mathrm{m} 2$, and the absolute horizontal accuracy is $0,5 \mathrm{~m}$, the vertical accuracy is $\pm 0,15 \mathrm{~m}$ (1 Table, Fig. 2).

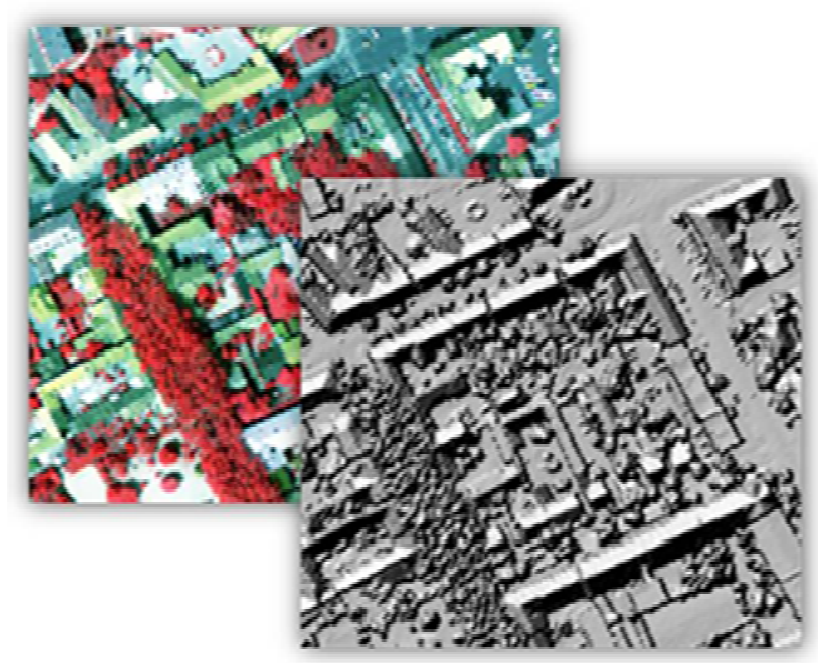

Fig. 2. Airborne photograph and Digital Surface model based on LIDAR 
Table 1. The specification of remote sensing data

\begin{tabular}{|l|l|l|}
\hline \multicolumn{1}{|c|}{ Datasets } & \multicolumn{1}{|c|}{ Spectral resolution } & \multicolumn{1}{c|}{ Other specification } \\
\hline $\begin{array}{l}\text { WorlView2 (2011, } \\
\text { 2017) }\end{array}$ & $\begin{array}{l}\text { Multispectral }(400-1040 \mathrm{~nm}), 8 \\
\text { bands, Panchromatic }\end{array}$ & $\begin{array}{l}\text { Spatial Resolution: PAN }-0,5 \mathrm{~m} \\
\text { MS }-2 \mathrm{~m}, \text { Quantization Level: 11 } \\
\text { Bits }\end{array}$ \\
\hline $\begin{array}{l}\text { Aerial photographs } \\
(2008,2009,2015)\end{array}$ & visible/infrared & Spatial Resolution: 0,5 m \\
\hline LIDAR (2008) & & $\begin{array}{l}\text { LIDAR point cloud FE/LE } \\
\text { Absolute accuracy: horizontal }< \pm 0.50 \\
\text { m; height }< \pm 0.15 \mathrm{~m}\end{array}$ \\
\hline
\end{tabular}

\subsection{Methodology}

One of the main objectives of this study was to develop a methodology to generate land cover classes of urban area from high spatial resolution satellite images through objectbased classification. Using the eCognition software not only the spectral information but also the shape, compactness and other parameters can be employed for mapping. To extract buildings a combination of spectral (WorldView2) and LIDAR data contains elevation information were applied. The most relevant information about buildings is their different elevation compared to their surroundings. We used an object-oriented approach, which allowed context consideration during the classification process. A consideration of spatial context is very important for correct identification and classification of objects.

The aim of this papers is to describe the potential of object-based image analysis (OBIA) for urban land cover detection and mapping impervious surface within parcels using very high spatial resolution imagery.

\subsection{Object-oriented image classification}

The land cover classification system presented in this paper includes only the more generalized levels (first and second level). The classification system is capable of further refinement. Defining the categories, the next main view-points were considered: to give names to categories by simply using accepted terminology, to use remote sensing as the primary data source. The process considered spectral value and spatial characteristics of objects and it is included the following steps:

- Segmentation

- Feature extraction

- Object classification

- Refinement of classification based on spectral value and spatial characteristics of objects

- Final identification of categories

- Accuracy assessment

\subsection{Segmentation and feature extraction}

Segmentation of images is one of the main steps that have to be solved in the objectbased classification [1-2]. Segmentation is a process by which pixels are grouped into segments according to their spectral similarity and other criteria (shape, area, position etc.) [9]. At the beginning of segmentation, the heterogeneity criterion is thresholded by the user. This is done by choosing a scale factor and by fixing the weights of the colour and shape criteria, and the smoothness and compactness criterions as well. The multiresolution 
segmentation algorithm was run with different scale factors (10, 20, 30, and 40) while all other parameters were held constant (shape: 0.1 and compactness: 0.5 ; shape: 0.4 and compactness: 0.5 ). In general, a scale factor of 10 a shape factor of 0.1 and compactness of 0.5 produced the best results. The algorithm spectral difference was used to refine existing segmentation results by merging spectrally similar image objects.

One of the critical steps in image analysis is to determine the most relevant features and algorithms to be used in classification [1]. The eCognition works with objects and information of whole objects like as the spectral signature, the shape and size or context is available. All these attributes can be applied and combined for classification. Features usually define the upper and lower limits of a range measure of characteristics of image objects. Image objects within the defined limits are assigned to a specific class, while those outside of the feature range are assigned to a different class (or left unclassified). Table 2. summarizes the features used to aid the classification process.

Table 2. The features used to aid the classification process

\begin{tabular}{|c|c|c|}
\hline Class & Main features & Other features \\
\hline $\begin{array}{ll}\text { Vegetation } & \text { (trees, } \\
\text { brushy, } & \text { grass, } \\
\text { barren) } & \\
\end{array}$ & NDVI & $\begin{array}{l}\text { Vegetation (trees, brushy, grass, } \\
\text { barren) }\end{array}$ \\
\hline Building & Height information & $\begin{array}{l}\text { Spectral features, NDVI, context } \\
\text { (Rel. Border to building), size } \\
\text { information }\end{array}$ \\
\hline $\begin{array}{l}\text { Other man-made } \\
\text { (road, other) }\end{array}$ & $\begin{array}{l}\text { Spectral information (NDWI, } \\
\text { NDVI) }\end{array}$ & size: area, length to width ratio \\
\hline $\begin{array}{l}\text { Parking place (big } \\
\text { area) }\end{array}$ & $\begin{array}{l}\text { Spectral information } \\
\text { NDWI) }\end{array}$ & $\begin{array}{l}\text { Shape: rectangular fit, shape index; } \\
\text { size: area, length to width ratio, } \\
\text { context: rel. Border to parking place) }\end{array}$ \\
\hline Water* & Spectral information (NDWI) & \\
\hline Shadows* & Spectral information (NDWI) & \\
\hline
\end{tabular}

\section{Results and discussion}

\subsection{Rule set based classification}

The classification of urban areas was done in two levels. In the first one the main categories of land cover were determined by taking advantage of spectral properties of WorldView2 image. In this process some normalized difference index was created according to the spectral mean data of determined classes in different bands. Normalized Difference Vegetation Index (NDVI) was used to select vegetation and no-vegetation and to investigate different kind of vegetation. Other indices also were developed and utilized during the classification (e.g. NDWI Normalized Difference Water Index). In the second level during the building extraction the elevation data was used as the most relevant characteristic of buildings. Additionally, the spectral and context features were employed to clarify the classification. Table 2 and Fig. 3 summarize the features, which were utilized to reveal the appropriate land cover classes. 

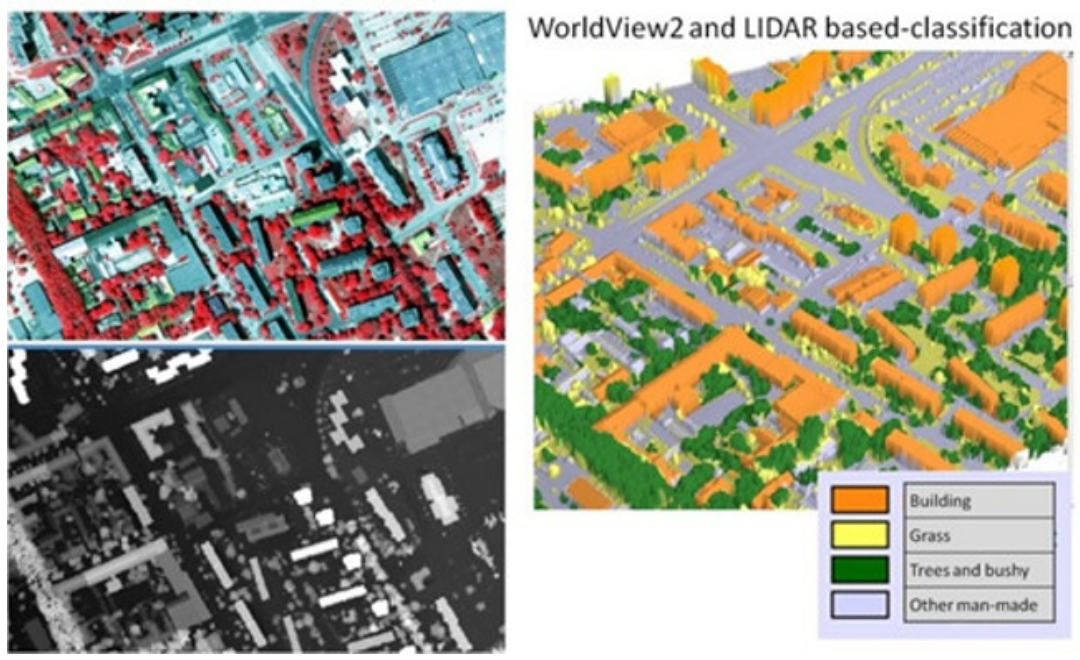

Fig. 3. Input data and the results of classification draped on DSM (Digital Surface Model based on LIDAR points)

\subsection{Performing accuracy assessment}

The results of the land cover classifications derived from remotely sensed data are compared by an accuracy assessment. An accuracy assessment analysis was performed by producing an error matrix that compared the interpreted land cover map and a map contains the result of ground truth investigation. The most important outputs from the accuracy assessment included an error matrix, errors of omission and commission, both for all classes and on a per category basis. The assessment indicates the producer's and user's and overall accuracy (Table 3).

Table 3. Accuracy assessment

\begin{tabular}{|l|c|c|}
\hline \multirow{2}{*}{ Class } & \multicolumn{2}{|c|}{ LIDAR and WorldView based classification } \\
\cline { 2 - 3 } & Producer's accuracy \% & User's accuracy \% \\
\hline Building & 88 & 99 \\
\hline Parking place & 96 & 99 \\
\hline Road & 67 & 92 \\
\hline Other man-made & 97 & 26 \\
\hline $\begin{array}{l}\text { Vegetation (trees- } \\
\text { bush) }\end{array}$ & 98 & 54 \\
\hline Grass & 94 & 51 \\
\hline \multicolumn{2}{|c|}{ Overall accuracy: 82 } \\
\hline
\end{tabular}

\subsection{Mapping impervious surface}

In this process other kind of segmentation (super object) were used to determined objects representing the parcels and all types of parcels were identified at super object level. To identity impervious surface within the parcels a new segmentation level (sub object) was 
added and the parcel area has been split up into image objects suited for identifying impervious surface. In the classification process the objects were assigned into two classes, vegetation and impervious surface. The final step of this work focus on categorizing parcels based on the degree of impervious surface. Four classes have been distinguished using the "classification" algorithm. The class distinction was based on imperviousness, in steps of $25 \%$ (Fig.4). The process is included the following steps:

1. Identify parcels (super object level)

- Segmentation representing the parcels (cheesboard segmentation)

- Classify the parcels (thematic layer attributes)

2.Identify impervious surface within the parcels (subobject level)

- A segmentation representing impervious surface (multiresolution segmentation)

- Classify impervious surface

3. Categorize parcels (classification, class description)

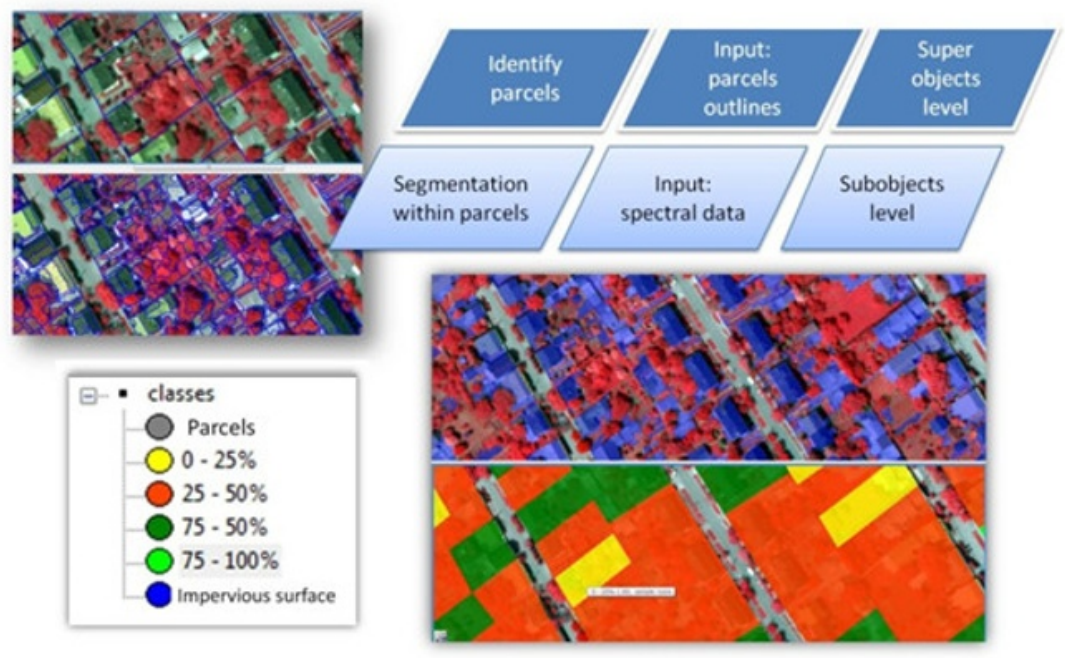

Fig. 4. Mapping impervious surface within the parcels

\subsection{Urban landscape extraction using high spatial resolution imagery and GIS techniques}

In this process a raster analysis GIS tools like focal and zonal function we used for urban landscape extraction. It included the following steps:

1. Segmentation

- Cheesbroad segmentation using thematic layer (Level 1)

- Cheesbroad segmentation 1 hectare units (Main Level)

- Multi resolution segmentation using mainly (0.9) the spectral information (Working Level)

2. Object classification

- Spectral values of 8 bands, indexes

- Position

- Relation to super object

In the classification process the objects were assigned into two classes, vegetation and water. Water bodies and vegetated area composed the class of Blue \& Green Area (BGA). The rest of the object was denoted as non-vegetated surface. To reach this classification 
firstly the vegetated area and lakes were separated and merged into one common class. The portion of BGA in one hectare was the final result of the classification and it was export out from the eCognition software as raster file. Two basic raster analysis tools were run on the exported data. Focal functions process data using different neighbourhoods cells. During the application of the zonal statistics tool of ArcGIS 9.3 software the polygons of district dataset calculated the statistics of raster layers were produced by neighbourhoods tool. The summary statistics of the zonal function is suitable to reveal the following information:

- Majority - the BGA value that appears most often in a given district,

- Range - range of the BGA values; homo- or heterogeneity of the BGA values in a given district

- Std - Standard deviation of BGA values in a given district

The outcome of our research confirms the original assumption that from the city center BGA value started to increase. The city center has the lowest BGA value, and there was not any cell which was covered more than $90 \%$ by BGA. The majority of the pixels BGA value is between $50-20 \%$ (Fig. 5).
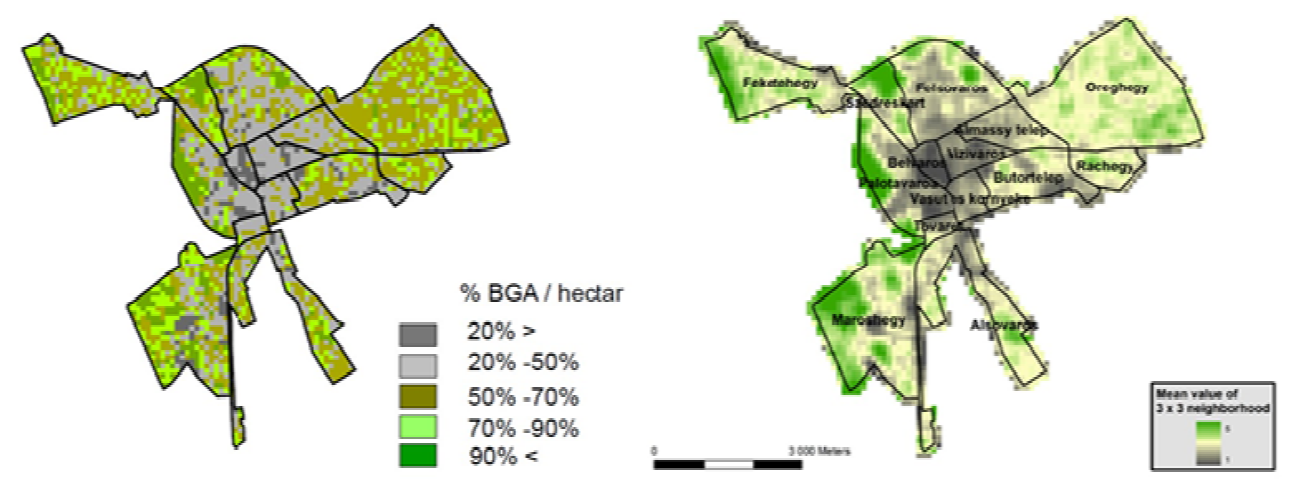

Fig. 5. BGA \% in one hectare

Employing zonal statistic functions other aspects of urban landscape were analyzed. According to urban morphological zone the statistical parameters of the district also were dissolved (Table 4) Five categories were used according to the Urban Atlas of European Union (URBAN ATLAS 2010). Value one demonstrate more than $90 \%$ of VBA value, and category 5 shows more than $80 \%$ of sealed or anthropogenic surfaces.

Table 4. Different statistical parameters of the urban morphological zones

\begin{tabular}{|c|c|c|c|c|c|c|}
\hline $\begin{array}{c}\text { Morphological } \\
\text { zone }\end{array}$ & $\begin{array}{c}\text { Maximum } \\
\text { value }\end{array}$ & $\begin{array}{c}\text { Range } \\
\text { value }\end{array}$ & $\begin{array}{c}\text { Mean } \\
\text { value }\end{array}$ & $\begin{array}{c}\text { STD } \\
\text { value }\end{array}$ & $\begin{array}{c}\text { Major } \\
\text { value }\end{array}$ & $\begin{array}{c}\text { Minority } \\
\text { value }\end{array}$ \\
\hline Downtown & 4 & 2 & 3,5 & 0,5 & 4,0 & 2 \\
\hline Village like & 5 & 5 & 1,8 & 1 & 1,6 & 5 \\
\hline Traditional & 4,8 & 4,8 & 2,4 & 0,7 & 2,8 & 3 \\
\hline $\begin{array}{c}\text { House with } \\
\text { garden }\end{array}$ & 5 & 5 & 1,8 & 0,75 & 2,0 & 5 \\
\hline Building estate & 4,75 & 4,5 & 2,3 & 0,9 & 2,2 & 4 \\
\hline
\end{tabular}

An additional result was calculated the neighborhood of 1 hectare BGA area around a given cell, to highlight the accessibility of natural environment of examined cell. Our results are able to explain the reason behind recent population trends of Székesfehérvár. Using focal function and calculating the maximum BGA value in 5 cells distance 
highlights, that the most of the historical center of the city does not have any area, which can provide 1 ha green area for the young inhabitants. This is one of the main motivation, why the young families leave the downtown and separating their living and working environment.

\section{Conclusion}

An urban ecosystem presents a wide structural diversity and consequently spectral variability therefore the process of classification needs not only spectral information but other information like context or geometry as well. The fusion of remote sensing techniques (imagery and aerial LIDAR) offers an efficient way to map and update GIS ready land cover information. Using enhanced data source and object based image analysis accurate results could be obtained.

Accuracy measures have shown that the use of elevation parameters leads to significant improvements in comparison to only spectral bands classifications. However, the best classification results were reached with the application of combined dataset of spectral and elevation features, the further studies are needed in this field. The accuracy of this method can be increased by integrated using high resolution aerial photos or hyperspectral data. Our study presented a multifaceted method to evaluate an index, which is able to represent one of the most important elements of the urban landscape. Object based image analysis and further GIS functions supplied useful information of inner pattern of Székesfehérvár and clarify some reason of present population trend.

\section{References}

1. T. Blaschke, ISPRS J. Photogramm. Remote Sens. 65, 2 (2010)

2. C. Burnett, T. Blaschke, Ecol. Modell. 168, 233 (2003)

3. I. Fekete, D. Dezső, I. László, K. Ócsai. Information Technology in higher education is an electronic publication (Debrecen, 2008)

4. S. Hartling and others, doi: 10.3390/s19061284 (Published online, 2019)

5. KSH 2014, Gazetteer of the Republic of Hungary (Online: http://portal.ksh.hu/docs/hun/hnk/hnk_2011.pdf, 2015)

6. D. Lu, S. Hetrick, E. Moran, Photogramm. Eng. Rem. S, 76, No 10, 1159 (2010)

7. S. W. Myint, P.Gober, A. Brazel, S. Grossman-Clarke, Q. Weng, Remote Sens. Environ. 115 (5), 1145 (2011)

8. R. Pu, S. Landry. Yu, Qian, Int. J. Remote Sens. 32 (12), 3285 (2011)

9. E. Schöpfer, S. Lang, J. Strobl: In: Rashed, T. - Jürgens, C. (Eds): Remote Sensing of Urban and Suburban Areas, 181 (Springer, Dordrecht, 2010)

10. R. Valbuena, T. F. de Sevilla, F.Mauro, C. Pascual, Abril, Martín, A. G. S., J. A. Manzanera, Lidar and true-orthorectification of infrared aerial imagery of high Pinus sylvestris forest in mountainous relief (Edinburgh, UK http://oa.upm.es/3104/2/INVE_MEM_2008_53075.pdf, 2008)

11. M. Veröné Wojtaszek, L. Ronczyk, Object based classification of urban land cover extraction using high spatial resolution imagery (2012)

12. Q. Weng, J. Remote Sens. Environ. 117, 34 (2012)

13. Y. Zhang, J. Photogramm. Remote Sens., 54 (1), 50 (1999) 
14. W. Zhou, G. Huang, A. Troy, M. L. Cadenasso, J. Remote Sens. Environ, 113, 1769 (2009)

15. S.Abdurakhmanov, Diss. Autoref. (TIIAME, Geodesy and Geoinformatics, 2020)

16. L. Gulyamova, J. Geograph. Societ. Uz. Spacial Vol., 28 (2018)

17. M. Sultanov, Research. Diss. (NUUz, 2018)

18. M. Herold, S. van der Linden, P. Hostert, D. Roberts, J. Urban Remote Sens. 137 (2006) 